\title{
Psychiatry, a Secular Discipline in a Postsecular World? A Review
}

\author{
Ricko Damberg Nissen 1,2,3,* (D), Frederik Alkier Gildberg ${ }^{1,3}$ and Niels Christian Hvidt 2 (i) \\ 1 Department of Psychiatry, Psychiatric Hospital Middelfart, Middelfart 5500, Denmark; \\ Frederik.Alkier.Gildberg@rsyd.dk \\ 2 Research Unit of General Practice, Institute of Public Health, University of Southern Denmark, \\ Odense C 5000, Denmark; nchvidt@health.sdu.dk \\ 3 Center for Psychiatric Nursing and Health Research, Institute of Regional Health Research, Faculty of \\ Health Science, University of Southern Denmark, Middelfart 5500, Denmark \\ * Correspondence: rnissen@health.sdu.dk; Tel.: +45-4291-0847
}

Received: 17 November 2017; Accepted: 16 January 2018; Published: 22 January 2018

\begin{abstract}
Postsecular theory is developing in academic circles, including the psychiatric field. By asking what the postsecular perspective might imply for the secular discipline of psychiatry, the aim of this study was to examine the postsecular perspective in relation to the secular nature of psychiatry, by way of a narrative review. In a systematic search for literature, relevant articles were identified and analyzed thematically. Thirteen articles were included, and three intertextual themes were identified, which represented ongoing international dialogues in relation to psychiatry and religion - such as intervention, integration, identity, the religious or irreligious psychiatrist, and the multicultural setting of the discipline. Furthermore, the postsecular perspective reveals a (potential) bias against the religious worldviews inherent in the secular. Postsecular theory can contribute to the ongoing discussions of how psychiatry, as a secular discipline, approaches the religious in the lives of patients and psychiatrists.
\end{abstract}

Keywords: psychiatry; religion; secular; postsecular

\section{Introduction}

Psychiatry, as a modern scientific discipline, developed during the Enlightenment. The ambition was to establish psychiatry with a secular identity, clearly distinct from that of religion (Thielman 2007), which was thought to be destined to vanish in the wake of rationality and modernity. Since the second half of the 20th century, the world has been in a process of postcolonial globalization, and this has led to the West struggling to reidentify itself in a multicultural and pluralist world (Gandhi 1998). It seems that, in the current era, the religious and spiritual aspects of human life are as present and multifaceted as ever (Berger 2014). Scholars argue that we are, in fact, in a postsecular time, with a resurgence of interest in religion in the public and political spheres, and that this has been followed by a renewed interest from the academic sphere (Gorski et al. 2012; Habermas 2008; Nynäs et al. 2012). These discussions about the postsecular are also part of an ongoing debate about the secular, secularity, and secularism (Calhoun et al. 2011). In much the same way as the concept of modernity has evolved into an understanding that there are multiple modernities (Casanova 2011), so too has the concept of the secular been pluralized, to enable a similar understanding that cultural, geographical, and historical contexts influence how the secular appears and functions in any given context (Breemer et al. 2014). And, what about that most secular of rooms-the room of the psychiatrist? Does the postsecular have any implications for the secular discipline of psychiatry? 


\section{Background}

As a Christian construct, secularism became a companion of the Enlightenment (Taylor 2007). Over time, the rationale developed that Western modernity would inevitably lead to the decline and eventual disappearance of religion, the secular would prevail, and the world would consist of modern secular societies modelled on the West par excellence (Berger 2014). Things turned out differently, however, and postcolonial times have seen not only crumbling empires (Ashcroft et al. 1995), but also the processes of globalization and multiculturalism. On the new global horizon, the Eurocentric concepts (such as the secular and religion) do not apply anymore-they have to be re-negotiated. In this process, the secular is being reincarnated, almost as an ironic self-fulfilling prophecy, as the sphere that contains the pluralist conditions (Madsen 2012). That this development has also influenced psychiatry can be seen in the reviews from within the discipline, which show a change in the way psychiatry understands and approaches the religious; it is moving away from the traditional, antagonistic view towards a more nuanced and inclusive understanding (Bonelli and Koenig 2013; Dein 2014; Koenig 2009). This can be recognized as part of the postsecular resurgence of interest in religion found across Western academia. When Habermas argued that it was Europe (and not the rest of the world) that was treading a deviant path ("Sonderweg") of modernity, he claimed that a society can be called postsecular in as far as it has to adjust to the continued presence of the religious in secular environments and under global influences, thereby renegotiating the secular to enable a legitimate presence of the religious in the public sphere (Habermas 2008). Since then, the postsecular has developed as a theoretical approach to understanding the continued entwinement of the secular and the religious (Nynäs et al. 2012).

In this article, we define the postsecular as the understanding that the religious aspects of human life continue to be present in and influence the human realm, including its secular inspirations (Nynäs et al. 2012). This definition of the concept enables a renegotiation of the secular. In this light, the secular is seen as secularization at the institutional level: the historical and theoretical separation at the organizational level of religious institutions from secular institutions (state, economics, science, politics, health, education, welfare, and so forth) (Casanova 2009). This is supplemented by an understanding of the secular at the individual level as the capacity of the individual to move in and out of relevance and plausibility structures (Berger 2014), at various levels of conscious reflection. This means that the religious is continuously being carried into and out of secular institutions and that there is an intertwinement of the two (Breemer et al. 2014), whereby the secular space as a strictly nonreligious space is compromised. The secular space is secular in theory and construction, but can be populated by religious and irreligious people alike. Finally, we entertain the understanding of secularities in the plural (Breemer et al. 2014), in that the cultural, geographical, and historical contexts co-define how the secular appears in context.

The concept of religion is taken in the widest possible understanding to keep it as open as possible; and for the same reason. As part of the narrative of this article, an (initial) re-negotiation of the concept becomes relevant. We do this through the concept of vernacular religion (Lassander 2012). We also introduce the concept of post-secular authenticity (Mendieta 2012).

\section{Aim}

The aim of this study was, through a narrative review of the existing research literature, to examine the implications of the postsecular for psychiatry as a secular discipline.

\section{Method}

As a result of the hypothesis inherent in the aim, that the postsecular has implications for psychiatry, a narrative review approach was preferred, because it allowed for connections to be made between, and a synthesis of information from, studies that might have different areas of focus, forms, and methodologies (Baumeister and Leary 1997). A literature search was conducted with the keywords 
and the keywords variables shown in Table 1 and was based on the aim and background of this article (Gildberg et al. 2010; Green et al. 2006). The search was done in the databases ATLA Religion, PubMed, Scopus, and SocINDEX. The located files were exported to a citation manager and read on three levels: 1. Title, 2. Abstract, and 3. Full Text. The abstract and full text readings were approached with the following inclusion criterion in mind: Does this article directly or indirectly report, contain, or investigate topics relating to the aim of this article? (Gildberg et al. 2010) In line with the understanding of the secular as a plural term, further criteria for inclusion were added: diversity of geographical (contextual) origin and diversity of approach. Seeing the postsecular as a sociological development over the last three to four decades, a diversity of year of publication was sought. The inclusion criteria are listed in Table 1.

Table 1. Literature Search.

\begin{tabular}{ll}
\hline Keywords Set in Title: & psychiatr* and religio* and secular* \\
\hline 'or' Variables: & mental health, spiritual ${ }^{*}$, postsecular* \\
\hline & $\begin{array}{l}\text { Peer reviewed; abstract and full text available; } \\
\text { relevant to the aim of the article; geographical } \\
\text { (contextual) diversity; diversity of approach; diversity } \\
\text { of publication year }\end{array}$ \\
\hline
\end{tabular}

\section{Results of the Literature Search}

The search was conducted on 4 November 2016 and returned 2155 files. The files were exported to the citation manager, and duplicate files were removed $(\mathrm{N}=12)$. On reading the files at level 1 (Title) and in relation to the inclusion criteria, 1988 files were excluded. The remaining 155 articles were read at level 2 (Abstract), and a further 123 articles were excluded. The remaining articles $(\mathrm{N}=32)$ were read at level 3 (Full Text). Of these, 19 articles were removed on the basis of the inclusion criteria of contextual diversity and diversity of approach. In the end, 13 articles were included (Table 2). The article by Pattison (Pattison 1978a) is the first part of two linked articles. The second article was also retrieved and they are considered here as one article. The article by Murken is part of an invited essay (Khalili et al. 2002) and, here, is referred to as Murken 2002. Pattison (1978a, 1978b), Carr (2000), and Murken (2002) also represent a diversion in the year of publication. The literature matrix (Table 2) includes the name(s) of the author(s), title of the article, journal, and geographical origin. The list was categorized by year of publication, with the most recent first (Table 2).

Table 2. Literature Matrix.

Jones N., Kelly, T. and Shattell, M. (2016). God in the brain: Experiencing psychosis in the postsecular United States. Transcultural Psychiatry, Vol 53 (4), 488-505. (USA).

Ulland, D. and DeMarinis, V. (2014). Understanding and working with existential information in a Norwegian adolescent psychiatry context: a need and a challenge. Mental Health, Religion \& Culture, Vol 17, No 6, 582-93. (NOR).

Pajevic, I. (2012). Secular and postsecular psychiatry. Psychiatria Danubina, Vol 24, Suppl. 3, 262-66. (BIH).

Crossley, D. (2011). Secular psychiatry and the self. Mental Health, Religion \& Culture, Vol 14, No 1, 31-34, Taylor \& Francis Ltd. (UK).

Cook, C.C.H., Powell, A., Sims, A. and Eagger, S. (2011). Spirituality and secularity: professional boundaries in psychiatry. Mental Health, Religion \& Culture, Vol 14, No 1, 35-42. (UK).

Durá-Vilá, G., Hagger, M., Dein, S. and Leavey, G. (2011). Ethnicity, religion and clinical practice: a qualitative study of beliefs and attitudes of psychiatrists in the United Kingdom. Mental Health, Religion \& Culture, Vol 14, No 1, 53-64, Taylor \& Francis Ltd. (UK).

Poole, R. and Higgo, R. (2011). Spirituality and the threat to therapeutic boundaries in psychiatric practice. Mental Health, Religion \& Culture, Vol 14, No 1, 19-29, Taylor \& Francis Ltd. (UK). 
Table 2. Cont.

\begin{tabular}{l} 
Hornborg, A. (2010). Designing rites to re-enchant secularized society: new varieties of spiritualized therapy in \\
contemporary Sweden. Journal of Religion and Health, 51, 402-18, published online 2010, Springer. (SWE) \\
\hline Murken, S. (2002). Invited Paper. Religion and mental health in cultural perspective: Observations and \\
reflections after the first International congress on religion and mental health, Tehran, 16-19 April 2001. \\
The International Journal for the Psychology of Religion, 2 (4), 217-37, Lawrence Erlbaum Associates Inc. 2002. \\
(GER). \\
\hline Greenberg, D. (2001). A Religious Psychiatrist's Ethnographic Self-Report. American Journal Of \\
Psychotherapy, Vol 55, No 4, 2001. (ISR) \\
\hline Coyle, B. R. (2001). Twelve myths of religion and psychiatry: Lessons for training psychiatrists in spiritually \\
sensitive treatments. Mental Health, Religion \& Culture, Vol 4, No 2, 2001, Taylor \& Francis Ltd. (USA). \\
\hline Carr, W. (2000). Some reflections on spirituality, religion and mental health. Mental Health, Religion \& Culture, \\
Vol 3, No 1, 2000, Taylor \& Francis Ltd. (UK). \\
\hline Pattison, E.M. (1978). Psychiatry and Religion Circa 1978: Analysis of a decade, Part 1. Pastoral Psychology, \\
Vol 27 (1), Fall 1978, Human Sciences Press. \& Psychiatry and Religion Circa 1978: Analysis of a decade, Part 2. \\
Pastoral Psychology, Vol 27 (2), Winter 1978, Human Sciences Press. (USA). \\
\hline
\end{tabular}

\section{Analyzing the Articles}

The articles were positioned in their respective context of origin, journal, and year of publication (Table 2). Then, they were read inductively, noting emerging themes (Zoglowek 1999), and subsequently coded, guided by the aim of this article as an analytic tool (Gildberg et al. 2015) and by asking: What implications does the postsecular have for psychiatry as a secular discipline? Through this process, three intertextual themes were established (Table 3), and the articles were read comparatively in relation to the themes and discussed in relation to the background literature and aim.

Table 3. Themes.

\begin{tabular}{c}
\hline Theme: Religion in psychiatry (intervention, integration, and identity) \\
Theme: The neutral psychiatrist \\
Theme: The (multi)cultural setting of psychiatry and religion \\
\hline
\end{tabular}

\section{Theme: Religion in Psychiatry (Intervention, Integration, and Identity)}

This theme is about how religion can be used as an intervention and how, in doing so, this could raise problems or dilemmas in relation to the religious worldview of the patient. This is further complicated by the fact that religious methods or techniques can be culturally appropriated, secularized, and integrated into psychiatry as purely secular techniques, leading to a discussion of the identity of psychiatry as a secular discipline.

Within the medical discourse of psychiatry, attention can be given to religious modalities in patients' lives. As an "intervention", this may not, at first hand, seem problematic. Psychiatry is a secular health discipline, and as such the subject matter of psychiatry is the improvement of the mental health of the patient. Religion can have potentially positive, negative, or no influence on the mental health of the patient. However, using religion as an intervention raises an ethical objection, illustrated by Coyle: "The literature is increasingly clear that spiritual and religious activities are highly preventive for substance abuse and dependence. Thus, we as practitioners are faced with a highly effective intervention for treating a difficult illness, but a treatment recommendation that could and would be considered coercive and unprofessional" (Coyle 2001, p. 159).

From the perspective of the religious specialists' insider, Carr (2000) has a different concern: "It (faith) becomes a type of cure, whereas most religions treat faith as an invitation to put life into a different and transcendent context. Belief is a summons to a pilgrimage rather than the offer of a solution or medicament" (Carr 2000, p. 9). Where the psychiatrist may see a possible intervention, 
the religious patient may not. For the religious patient, religion may represent an Archimedean point around which everything else revolves. While acknowledging the presence of positive aspects of religion in relation to health, Carr maintains that, in a multicultural society, any kind of psychiatric treatment has to be culturally sensitive to the individual patient. "Behaviour that may be acceptable in one culture may be interpreted in another as a sign of illness" (Carr 2000, p. 5), and until this is culturally resolved, i.e., is sensitive to a specific religion or spirituality, religion as an intervention remains problematic (Carr 2000, p. 5). This understanding gets support from Murken who, while reflecting on differences between researchers from the United States and Pakistan, illustrates the opposing understandings. "For the researcher from the United States, it was simply choosing sets of variables (religion being one of them) ... For the researcher from Pakistan, religion seemed to be the very foundation of his scientific inquiry" (Murken 2002, p. 228). "Religion is not one cultural subsystem among others but the basis and framework of everything else. It is a primary, non-reducible phenomenon" (Murken 2002, p. 229).

In the highly secular context of Sweden, Hornborg posits a situation illustrating the thoughts of Carr and Murken from another perspective. In a process of desecularization, Hornborg finds that religious traditions are lifted out of their original context, i.e., they are culturally appropriated, precisely as if they were reducible cultural subsystems-to use Murken's words. They can be moved around at will, secularized and embedded in secular institutions, such as psychiatry. Reduced to and marketed as nonreligious, pure secular practices or techniques, Hornborg stresses that "no traditional religious practice is reducible to a mere secular technique" (Hornborg 2010, p. 404). In a secular context, such as Sweden, this process compromises both the position of psychiatry as a secular discipline (Hornborg 2010, p. 404) and the religious worldview of the patient, as positioned by Carr and Murken. Interestingly, Coyle differs decisively in his understanding of this situation. "Fortunately, within the substance abuse treatment arena, we have found a clandestine way of including spiritual forces in care. This is, of course, that of Alcoholics Anonymous which has its fundamental basis in spiritual principles and practice" (Coyle 2001, p. 159). Furthermore, this entwinement has become so accepted in the US that "failure to make such a recommendation might be considered inadequate care" (Coyle 2001, p. 159).

Similar to Hornborg, Crossley asks what is at stake when a religious tradition-such as the Buddhist concept of "mindfulness" — is integrated into a secular psychiatric discipline: "Are these developments simply an unproblematic matter of borrowing values and techniques from religious traditions in secularized form? Or is something more being imported into mental health practice?" (Crossley 2011, p. 32). Continuing this argument from another perspective, Poole et al. (UK) stress that, if psychiatry is to be regarded as a legitimate medical scientific discourse, it has to be distinctively clear in its definition and identity as an applied science, and "practiced within a set of explicit formal values that are well understood by patients and professionals alike" (Poole and Higgo 2011, p. 22). From a sociocultural perspective, Pajevic points out that psychiatry as a medical discipline is always socially situated in a (multi)cultural context, and therefore influenced by the same processes as the rest of society, and that, if a clear distinction can be kept between the two, they may supplement each other (Pajevic 2012, p. 265). "In this way psychiatry does not lose its 'scientific component' because the spirituality, beliefs or effects of religious practices on mental health can be scientifically investigated without crossing the boundaries between the natural and spiritual sciences" (Pajevic 2012, p. 266).

In their research involving immigrant psychiatrists in the UK, Dura-Vila et al. also found reflections on the need for the discipline to have a clear identity, but also just how difficult this is in relation to religion in a multicultural setting. The immigrant psychiatrists were reluctant to address religious issues for fear of not fitting into the secular context and downplayed their own religiosity in the process of integration into a new secular context (Dura-Vila et al. 2011, p. 57). Ambiguous about the place and role of religion in psychiatry in the UK, the immigrant psychiatrists pointed out that religion was routinely assessed in their home countries, while it was excluded in the UK (Dura-Vila et al. 2011, p. 56). The UK-born psychiatrists, while considering religion to 
be an important issue, did not " ... routinely incorporate these aspects in their clinical practice: they do not inquire about them while assessing a patient nor include them as part of treatment" (Dura-Vila et al. 2011, p. 58).

In Norway, a secular vocabulary, such as "existential information" and "existential meaning-making", is used as a way of approaching the religious in psychiatry (Ulland and DeMarinis 2014, p. 584). Individual psychiatrists also include a reflection of the "personal background and existential orientation embedded in the sociocultural context of the therapist" (Ulland and DeMarinis 2014, p. 590). Sociocultural competency, as a framework for understanding and working with the existential dimensions of patients' lives, appears to be of great importance (Ulland and DeMarinis 2014, p. 590).

\section{Theme: The Neutral Psychiatrist}

In focus in this theme are the implications for psychiatry in the acknowledgement that the cultural and religious identity of the psychiatrist does not constitute a neutral position. This has led to a more nuanced and (self-)reflected understanding of the influence that the cultural and religious identity of the psychiatrist has on the therapeutic relationship and on the (historic) place and role of the religious in psychiatry, but also of the implications of mixing the religious-cultural and the scientific-medical discourses.

On the individual level, the untenable position of the neutral psychiatrist is pointed out by Greenberg. "It has become increasingly clear that such neutrality is more assumed than real and that many aspects of the therapist's identity is present to the patient" (Greenberg 2001, p. 564). A similar objection is pointed out by Pattison. "We suffer from the illusion that we can offer a culture-free, value-free, ideology-free cure for the human condition under the universalistic rubric of mental health" (Pattison 1978a, p. 13). While still in place, this illusion of neutrality is a structure that safeguards the psychiatrist. When this illusion crumbles, however, it becomes necessary to (re-) establish the discipline in a way that can encompass this renegotiated position of the psychiatrist, unless the discipline is to reverse into (postmodern) relativity. Ulland and DeMarinis argue that this can be done through a shift in the vocabulary used, as mentioned in the previous theme, in the attempt to create a "secular base" that can steer clear of any specific value orientation with which the individual psychiatrist might be affiliated. This has to be combined with training, information, and individual self-reflection (Ulland and DeMarinis 2014, p. 590). In relation to the notion that the secular represents a neutral territory, Cook et al. raise a concern regarding the presupposition that the secular is " ... 'neutral' ground, when in fact it is not. It is deeply biased against the transcendent" (Cook et al. 2011, p. 37). From this perspective, and building on Charles Taylor's "A Secular Age" (Taylor 2007), they suggest that a secular psychiatry might be "the result of 'hidden closed world structures' which distort the appearance of reality, more than protective mechanisms which preserve healthy professional or ethical boundaries or defend personal religious belief" (Cook et al. 2011, p. 37).

Dura-Vila et al. suggest multicultural training as a possible way to approach the religious in psychiatry that might circumvent the problem, anticipating an atmosphere "... where topics about religion/spirituality can be discussed amongst colleagues and where migrant psychiatrists could be encouraged to become 'cultural experts'" (Dura-Vila et al. 2011, p. 62). Apart from the immediate danger of becoming just another form of cultural imperialism, the "cultural expert" might have something to offer, in that, implicit in the term, is the fact that it is not neutral; it is positioned in a religious and cultural familiarity that could, in fact, facilitate the psychiatrist's work.

Coyle points out the psychiatrist is “ ... operating within professional fiduciary responsibility to provide the best care for the patient over any personal interest" (Coyle 2001, p. 154), while the patient "... assumes that the physician is wiser, more balanced, has more coping resources or is at least 'healthy enough' to assume the role of 'healer' in the therapeutic relationship" (Coyle 2001, p. 154). This powerful position of the psychiatrist, the vulnerable position of the patient, and the untenable neutral position are argued by Poole et al. as being decisive. "Psychiatrists and other mental 
health professionals are not neutral in matters of faith or conviction, but they have to take a stance of neutrality in many matters, in order to protect patients" (Poole and Higgo 2011, p. 23). That this is easier said than done is illustrated by Greenberg when reflecting on giving advice to a religious Jewish patient.

"I am explaining to a patient the basis of exposure treatment for phobias.... As is its way, the Midrash brings a parable: If a man is afraid of a pack of dogs he should go and sit among them until his fear subsides. (Genesis Raba 84:3). 'So we see', I continue 'that this way of treating phobias is according to the Midrash and Maimonides'. I cannot help feeling a fraud and manipulator. I use the treatment because of the research done on exposure and not because of the Midrash. If my reason for using exposure is because of the research, and the patient accepts the treatment because of the Midrash, am I being dishonest?" (Greenberg 2001, pp. 573-74).

While using religion as an intervention, Greenberg does it from a self-reflected and culturally-reflected position. However, even though he is of the same religious and cultural background as the patient and as such is acting as a "cultural expert", he is still ethically concerned about "mixing" the cultural and scientific discourses. The findings of Jones and Shattell (USA) add an interesting perspective. They found that some mental health patients "... used a science-like language or logic to legitimize religious interpretations of particular experiences, others used a faith-like language to explain scientific interventions, including medications" (Jones et al. 2016, p. 489), asserting "the supernatural reality of their experiences at the same time that they frame these experiences as clinical symptoms of an illness" (italics in original) (Jones et al. 2016, p. 494). Maybe Greenberg's patient would also have been able to entertain and accept a medical approach legitimized in religion? The intertwinement of discourses illustrated here in both patient and psychiatrist is reminiscent of the process of desecularization in psychiatry (Pajevic 2012, p. 263), but it also complicates the perspective that psychiatry can maintain its essence as a medical discipline (Pajevic 2012, p. 265), whilst in the process of desecularization.

Along the lines of Ulland and DeMarinis, Pajevic has a list of things that the psychiatrist should appreciate and reflect upon when approaching religiosity and spirituality: " . . the changes in attitude towards the spiritual and religious in the process of patients' evaluation, quality of life assessment, respect for the spiritual needs of patients in the process of clinical treatment, as well as objective consideration of the phenomenon of religiosity by psychiatrists ... " (Pajevic 2012, p. 263). Pajevic sees this as a move towards a postsecular psychiatry that can offer a more reflected position, although a clear explanation of what is meant by "objective consideration of the phenomenon of religion" and "spiritual needs" is necessary, if it is to be of any social scientific value and use. Still, this process reinitiates the concern of the clear identity, by risking an arbitrary or idiosyncratic mix of science and religion. To overcome this, Carr argues that, in some cases, the cooperation between the psychiatrist and the religious expert could establish an understanding of the religious context of the patient (Carr 2000, p. 9), echoing the "cultural expert" suggested by Dura-Vila et al. (p. 62). How this cooperation is to be facilitated, and where and how they can meet on par in a multicultural and pluralist context is not easily resolved, especially if one bears in mind that the secular could be acting as a barrier in this, and it could involve an a priori placement of one expert above the other, if the argument of Cook et al. (p. 37) is followed. This difficulty is also illustrated by Dura-Vila et al., whose informants recognize the importance of including the religious as part of their practice, but who "... have never liaised with religious professionals" (Dura-Vila et al. 2011, p. 58). The personal reflections of Greenberg, acting again in the role of the "cultural expert", are informative of both the ethical dimension and the complexity of the position.

"I have offered treatment but the patient declines as, he tells me, he puts his trust in God. On the tip of my tongue is the commentary on the phrase in the Torah (Exodus 21:19) that states: 'From here we learn that doctors were given by God the power to heal'. It is this sentence that makes it a duty to seek medical help, and to be willing to break the rules of Sabbath observance in order to receive 
this help. I stop myself from telling him. I tell him he must go to his rabbi to discuss this refusal" (Greenberg 2001, p. 573).

Remembering the findings of Jones and Shattell, this quote from Greenberg illustrates a situation where the two discourses could have been consciously entwined using one (religion) to legitimize the other (medicine). However, it also illustrates the dilemma and question as to whether the psychiatrist should use religious knowledge to manipulate a patient, or if this is a breach of professional boundaries, and that religious advice and counselling belong with the religious expert. Unsure of how to solve this, Greenberg is silent and refers his patient to the religious expert. Greenberg does not say whether or not he himself has discussed the situation with the Rabbi. Maybe a more formalized relationship between the two would enable a better understanding and treatment? Finally, the doubt that Greenberg feels illustrates the need to address this in order to both avoid idiosyncrasy and maintain the clear identity of the discipline.

\section{Theme: The (Multi)Cultural Setting of Psychiatry and Religion}

This theme is focused on the multicultural contexts and settings of both psychiatry and religion. This theme provides a contributory aspect to both of the two previous themes, but also shows how the multicultural might point to some potential solutions and ways forward.

In the multicultural and pluralist world, it is virtually impossible for the individual not to be aware of the existence of other religious (and irreligious) worldviews. Jones and Shattell (Boeve 2005) formulate it this way: “ ... secularism's disruption of the unquestioned and quasi-automatic transmission of tradition" has helped engender a social context in which "[religious or spiritual] identity is no longer given but has to be constructed" (Jones et al. 2016, p. 490). When this multicultural world is also a consumer culture, then religion becomes one among several products. This development includes an entwinement of psychiatry and religion, in which " ... mental health enterprises are no longer separate from religious enterprises in the common culture. There is no longer a psychiatric view and a religious view. Rather there are different views of the world and self that incorporate a particular blend of psychiatry and religion" (Pattison 1978a, p. 9).

This entwinement of secular and religious worldviews in the public sphere brings back into focus the notion of identity, in that both psychiatry and religion exist under these condition: they are "culturally located, and those involved, respectively, in each work in a multiethnic and multireligious society" (Carr 2000, p. 3), or they are socially situated in a multicultural context (Pajevic 2012, p. 265). Poole and Higgo bring another argument. "Denial that there is a difference between belief and evidence is a doctrine shared with some forms of post-modernism.... This doctrine is dangerous and leaves patients without protection from the idiosyncratic beliefs of the practitioner" (Poole and Higgo 2011, p. 26). The intertwinement of discourses brought about by the multicultural conditions is currently blurring the situation, while a cultural relativism looms. Furthermore, the legitimacy of psychiatry as a secular health discipline, endorsed by the state, comes under threat when faced with competing enterprises that mirror the academic credentials in titles "such as accredited, authorized, diplomized, licensed or certified, although without the academic qualifications" (Hornborg 2010, p. 408). "The clear-cut boundary between scientific, clinical practices that the secularized state promotes and the practices of New Age spirituality that formerly were seen as a completely private matter of the individual has collapsed" (Hornborg 2010, p. 415).

Another side to the idea of a constructed religious identity is touched upon by Crossley, namely that "religious adherence is not simply a matter of intellectual assent or opinion, personal preferences purchased, as it were, from a secular market place" (Crossley 2011, p. 33). As shown in the aforementioned two themes, the religious can range from the Archimedean point of view at one end of the spectrum, to a secularized technique at the other end. Add to this the aspect that the religious is (mostly) also culture-bound, inherited, socialized from birth, and carried by tradition, and there might not always be a choice. This perspective needs to be considered, because it is followed by the problem of the secular discourse legitimizing the secular cultural trait as the norm, while stigmatizing, or 
marginalizing, the religious cultural trait (Carr 2000, p. 5). This will inevitably lead to a clash between the two discourses, illustrating a problem in a secular, pluralist world. This is exemplified by Greenberg: "The professional organizations behind the DSM and ICD may have declared homosexuality not to be a disorder, but in religious Judaism it remains forbidden" (Greenberg 2001, p. 574). The secular law reigns above the religious law in a secular society: this is the quintessential point of secularizing in the first place. This is not a neutral position, however, as it strives to exclude religious truth claims. The secular is itself a biased model with a truth claim (Cook et al. 2011, p. 37). "The tantalizing question is whether these differing models with their different assumptions can be fruitfully contrasted and compared, and their cultural, religious, and psychological 'bias' be reflected and communicated" (Murken 2002, p. 230). The conscious and reflected entwinement of the two discourses comes back into play, but also the need to deconstruct the secular as a "doctrine" that can subordinate the potential therapeutic modalities of the religious. Jones and Shattell see this deconstruction as the postsecular in action, when they argue that the postsecular is a "cultural renegotiation of the religious as the presumptions of Western secularism begins to fray" (Jones et al. 2016, p. 489). This brings to light "a heightened recognition of the ongoing entanglements of supernatural and scientific discourse" (Jones et al. 2016, p. 489). They engage the postsecular in an attempt to reconcile the two discourses and their entwinement in the human mind. "Postsecular theory reminds us that even "normal" people regularly entertain contradictory beliefs or, perhaps more accurately, beliefs tied to incommensurable underlying logics.... An alternative interpretation, however, might hold that both faith and science, in their contemporary iterations, are nevertheless undergirded by common (tacit) epistemic principles and assumptions" (Jones et al. 2016, p. 489).

This is similar to the suggestion made by Pajevic of a renegotiated relationship between the discourses of natural science and religion as a possible method to be used in a postsecular context. Pajevic argues that a postsecular psychiatry can provide psychiatry with a more inclusive and reflected approach regarding the religious needs of patients, without compromising the boundaries between the two (Pajevic 2012, p. 266). Maybe the Norwegian reformulation of the religious in terms of "meaning-making" and "existential meaning", as " ... a culturally appropriate way of dealing with existential information in the psychotherapeutic context" (Ulland and DeMarinis 2014, p. 584), alongside the self-reflection of the existential (religious) orientation of the psychiatrist is an attempt to reach this position?

\section{Discussion}

Considering the historical antagonism between psychiatry and religion, it is clear that there has been a shift in the relationship between the two, where psychiatry to some degree has recognized religion, or the religious, as a more faceted human modality than earlier thought. This is part of the postsecular process, and that it is not a new thing is illustrated here by the inclusion of the article by Pattison from 1978-an article that is in itself postsecular. The postsecular as an ongoing process is also illustrated by the timespan between the articles-1978 to 2017. In psychiatry, the main shift in the relationship with religion is the focus on the potential capacities of religion as a positive influence on mental health. However, this change is not an easy change-as illustrated in the themes represented here. Within psychiatry, religion has been recognized as a potential intervention. For the religious patient, however, the religious is often the encompassing worldview and, therefore, it is not reducible simply to an intervention. Alongside this ambivalence runs the recognition that psychiatry, as a secular discipline in a multicultural, multiethnic, and pluralist world, needs to undergo a de- and reconstruction if it is not to be illusive. The secular could act as a marginalizing doctrine, blocking a deeper understanding of the religious human mind, and a renegotiation of the secular is needed-and is happening, as illustrated in the articles-within psychiatry to encompass this. This is further complicated by the compromised position of the neutral psychiatrist, but also by that fact that religious traditions are being culturally appropriated and introduced both into the discipline and in wider cultural contexts. The abovementioned issues are blurring the boundaries and the identity of the 
discipline. It is apparent from the articles here discussed that there is a strong need for psychiatry to have a clear identity. It is also apparent from a postsecular perspective, however, that this is difficult, because it involves developing a new and more inclusive relationship with both an understanding of and an approach to cooperation with the religious. From across geographical contexts and time, the presented articles illustrate this complex situation. Notable is the difference in approach or acceptance of the use of religious traditions embedded in the secular discipline in Sweden and USA, as illustrated by Hornborg and Coyle, respectively. This also illustrates more general differences between Europe and USA regarding the religious and the secular (Berger et al. 2008). However, there seems to be an almost unified focus throughout the articles on the attempt to include-rather than exclude-the religious. This is in itself a sign of the postsecular and, as such, the articles, in general, write themselves into what is becoming a postsecular tradition.

From a variety of geocultural contexts, the addressed problems and the proposed solutions are placed at both the individual level and the macro level, ranging from addressing the dangers of local and individual idiosyncrasies, to a macro-level inability to incorporate the religious, while maintaining an identity as a scientific discipline. In these renegotiations, the secular could be both a support and a hindrance. Argued as a potential "neutral" sphere, it could enable a multicultural and pluralist scene, where different religious worldviews can meet on an equal footing. However, this does not address or solve the problem of the secular in itself being biased against the religious, subjugating the potential positive modalities of the religious. The (secular) psychiatrist is placed in an ambiguous and unclear situation when faced with the religious. It is incumbent upon psychiatrists to recognize the obligation to respect the religious as part of the human and the potential that might lie inherent in the religious, but often they are unsure of how to approach religious issues, and thereby the same idiosyncrasy (or postmodern relativity) that needs to be avoided, will be the result. A range of possible approaches are suggested: information, training, change in vocabulary, cultural and religious (self-)reflection, the "cultural expert", and cooperation between religious and psychiatric experts. As an example, a well-defined cooperation between experts could enable "the exorcising of evil spirits as a vehicle for resolving the underlying psychological problems embedded in a specific cultural context" (Ruyter 2014, p. 210). As a legitimate-albeit controversial-approach in psychiatry, this cooperation would attempt to accommodate the "ongoing entanglements of supernatural and scientific discourse" (Jones et al. 2016, p. 489). It would invoke the "cultural expert", and a more nuanced understanding of the religious worldview of the individual patient.

We supplement the term "the religious" with the term "vernacular religion" (Bowman 2003; Lassander 2012) in order to highlight the significance of a de-reconstruction of the understanding of religion. Otherwise, the postsecular might end up as a concept that cloaks the inherent bias of the secular, aiding an unfortunate kind of secularism (Casanova 2009). Vernacular religion is the understanding that the religious is always situated at the local level, in the individual, and in the local language(s) (Lassander 2012). In line with this, although there are similarities between religious worldviews, any given religion will ultimately consist of as many different versions as there are followers of that particular religion. From this perspective, it becomes meaningless to argue that one person (the psychiatrist) can address the religious worldview of another person (the patient) on the basis of knowing what religion the person is affiliated with, and being affiliated with the same religion (cultural expert). The individual content and construction of one particular worldview, including the religious worldview, is entwined in a multitude of influencing factors, such as family, community, natural environment, cultural context(s), local, national, international, geographical, historical, political, economic contexts, communication medias, market forces, socialization processes, tradition, religious institutions, lack of religious institutions (Lassander 2012), and so on. On this basis, it would be biased to claim commonality with a person at anything but a superficial level. It becomes meaningless to talk about the reduction of religion to an intervention, because knowing that a person adheres to a specific religion, is not equal to knowing the specific worldview of that person. From this perspective, religion is not reduced to an intervention; instead, it becomes a concept to guide or inform about the realm 
of meaning-making, in which any given conversation is taking place, thereby being sensitive to the worldview of both the patient and the psychiatrist, and situating both in a local cultural context.

The postsecular concept can contain this, by recognizing the presence of the religious in the public (secular) sphere, the plurality of the secular, and the need to renegotiate the secular (scientific) and religious discourses. In relation to a discipline so intimately focused on the inner human life such as psychiatry, and with empathy as a decisive characteristic of the psychiatrist, this renegotiation seems almost imperatively important. The meeting between patient and psychiatrist (always) takes place at the local level between two (or more) individuals and their worldviews, and it can be drawn from the articles included here that this position needs to be (self-)reflected by the psychiatrist, because it is $\mathrm{s} /$ he who holds all the responsibility and power in the therapeutic meeting. It is also clear that this includes a reflection of personal religious affiliations, the religious per se, and the cultural context of the involved parties. These are not easy reflections to make, especially since they have to be made through research and national and international debate and cooperation, if idiosyncrasy and relativism are to be avoided. However, these reflections still need to be employed at the local level. If this is a postsecular approach, it (almost) inaugurates what Mendieta (following Habermas) coins the "post-secular authenticity". This is seen as a reflexive subjectivity that has "come of age, and that has freed itself of its "ethnocentric prison", so that it can now encounter other cultures on the other side of Eurocentric arrogance" (Mendieta 2012). When seen in relation to a pluralism of modernities, a pluralism of religious and secular discourses that undermine what is taken for granted in any given tradition and worldview (Berger 2014), perhaps a postsecular psychiatry could be sensitive to its own (secularly) biased position. Maybe this sensitivity already exists?

\section{Conclusions}

By viewing the postsecular as primarily a recognition of the (continuing) presence of the religious in human culture and a dialogue on how to enable this presence in the secular, this review has presented a broad focus in psychiatric research literature on (some of) the implications that the postsecular raises for psychiatry as a secular discipline. Over a period of time and from a variety of both cultural contexts and academic approaches, this postsecular recognition is present in the articles and reflected in the themes dealt with in this review. They contribute to the ongoing and required renegotiation of both the secular and the religious in relation to psychiatry, and postsecular theory does have something to offer in this endeavour, not least, the awareness of the potentially biased position of the secular and the ambiguity of the religious. The articles represented here all contribute in this process of continuously developing the relationship between psychiatry and religion in a multicultural and pluralist world.

Acknowledgments: The authors acknowledge funding from the Psychiatric Research Fund in the region of Southern Denmark, the Psychiatric Department Middelfart, Denmark, the Research Unit of General Practice, University of Southern Denmark, Odense, Denmark, and the Academy of Geriatric Cancer research, Odense University Hospital, Denmark.

Conflicts of Interest: The authors declare no conflict of interest.

\section{References}

Ashcroft, Bill, Gareth Griffiths, and Helen Tiffin. 1995. The Post-Colonial Studies Reader. London: Routledge, ISBN 0-415-09621-9.

Baumeister, Roy. F., and Mark R. Leary. 1997. Writing Narrative Literature Reviews. Review of General Psychology 1: 311-20. [CrossRef]

Berger, Peter. 2014. The Many Altars of Modernity. Boston and Berlin: Walter De Gruyter, Inc., ISBN 978-1-61451-750-4.

Berger, Peter, Grace Davie, and Effie Fokas. 2008. Religious America, Secular Europe? Aldershot: Ashgate, ISBN 978-0-7546-6011-8.

Boeve, Lieven. 2005. Religion after detraditionalization: Christian faith in a post-secular Europe. Irish Theological Quarterly 70: 99-122. [CrossRef] 
Bonelli, Raphael M., and Harold G. Koenig. 2013. Mental Disorders, Religion and Spirituality 1990 to 2010 : A Systematic Evidence-Based Review. Journal of Religion \& Health 52: 657-73. [CrossRef]

Bowman, Marion. 2003. Vernacular Religion and Nature: “The Bible of the Folk" Tradition in Newfoundland. Folklore 114: 285-95. [CrossRef]

Breemer, Rosemarie, Joes Casanova, and Trygve Wyller. 2014. Secular and Sacred? The Scandinavian Case of Religion in Human Rights, Law and Public Space. Göttingen: Vandenhoeck \& Ruprecht, ISBN 978-3-525-60449-6.

Calhoun, Craig, Mark Juergensmeyer, and Jonathan VanAntwerpen. 2011. Rethinking Secularism. Oxford: Oxford University Press, ISBN 978-0-19-979668-7.

Carr, Wesley. 2000. Some reflections on spirituality, religion and mental health. Mental Health, Religion E Culture 3: 1-12. [CrossRef]

Casanova, Jose. 2009. The Secular and Secularisms. Social Research 76: 1049-66.

Casanova, Jose. 2011. Cosmopolitanism, the clash of civilizations and multiple modernities. Current Sociology 59: 252-67. [CrossRef]

Cook, Cristopher C.H., Andrew Powell, Andrew Sims, and Sarah Eagger. 2011. Spirituality and secularity: Professional boundaries in psychiatry. Mental Health, Religion \& Culture 14: 35-42. [CrossRef]

Coyle, Brent R. 2001. Twelve myths of religion and psychiatry: Lessons for training psychiatrists in spiritually sensitive treatments. Mental Health, Religion \& Culture 4: 149-74.

Crossley, David. 2011. Secular psychiatry and the self. Mental Health, Religion \& Culture 14: 31-34. [CrossRef]

Dein, Simon. 2014. Religion and Mental Health: A Critical Review of the literature. Official Journal of World Association of Cultural Psychiatry WCPRR 9: 42-46. [CrossRef]

Dura-Vila, Gloria, Matthew Hagger, Simon Dein, and Gerard Leavey. 2011. Ethnicity, religion and clinical practice: A qualitative study of beliefs and attitudes of psychiatrists in the United Kingdom. Mental Health, Religion $\mathcal{E}$ Culture 14: 53-64. [CrossRef]

Gandhi, Leela. 1998. Postcolonial Theory; A Critical Introduction. New York: Columbia University Press, ISBN 0-231-11273-4.

Gildberg, Frederik, B. Elverdam, and Lise Hounsgaard. 2010. Forensic Psychiatric Nursing: A literature review and thematic analysis of staff-patient interaction. Journal of Mental Health Nursing 17: 359-68. [CrossRef] [PubMed]

Gildberg, Frederik, Stephen K. Bradley, Ellen B. Tingleff, and Lise Hounsgaard. 2015. Empirically Testing Thematic Analysis (ETTA) Methodological implications in textual analysis coding system. Nordisk Sygeplejeforskning 5: 193-207.

Gorski, Philip S., David K. Kim, John Torpey, and Jonathan VanAntwerpen. 2012. The Post-Secular in Question. New York: Social Science Research Council, New York: New York University Press, ISBN 978-0-8147-3872-7.

Green, Bart N., Claire D. Johnson, and Alan Adams. 2006. Writing Narrative Literature Reviews for Peer-Reviewed Journals: Secrets of the trade. Journal of Chiropractic Medicine 5: 101-17. [CrossRef]

Greenberg, Dave. 2001. A Religious Psychiatrists Ethnographic Self-Report. American Journal of Psychotherapy 55: 564-76. [PubMed]

Habermas, Jürgen. 2008. Notes on a post secular society. New Perspectives Quarterly 25: 17-29. [CrossRef]

Hornborg, Anne-Christine. 2010. Designing rites to re-enchant secularized society: New varieties of spiritualized therapy in contemporary Sweden. Journal of Religion and Health 51: 402-18. [CrossRef] [PubMed]

Jones, Nev, Timothy Kelly, and Mona Shattell. 2016. God in the brain: Experiencing psychosis in the postsecular United States. Transcultural Psychiatry 53: 488-505. [CrossRef] [PubMed]

Khalili, Shiva, Sebastian Murken, Helmut K. Reich, Ashiq A. Shah, and Abdolvahab Vahabzadeh. 2002. Religion and mental health in cultural perspective: Observations and reflections after the first International congress on religion and mental health, Tehran, 16-19 April 2001. The International Journal for the Psychology of Religion 2: 217-37. [CrossRef]

Koenig, Harold G. 2009. Research on Religion, Spirituality, and Mental Health: A Review. The Canadian Journal of Psychiatry 54: 283-91. [CrossRef] [PubMed]

Lassander, Mika. 2012. Grappling with Liquid Modernity: Investigating Post-Secular Religion. Post-Secular Society 2012: 239-67. 
Madsen, Richard. 2012. What Is Religion? Categorical Reconfigurations. In The Post-Secular in Question: Religion in Contemporary Society. Edited by Philip Gorski, David Kyuman Kim, John Torpey and Jonathan VanAntwerpen. London and New York: The Social Science Research Council and New York University Press.

Mendieta, Eduardo. 2012. Spiritual Politics and Post-Metaphysical Religion. In The Post-Secular in Question. Edited by Philip Gorski, David Kyuman Kim, John Torpey and Jonathan VanAntwerpen. New York: New York University Press.

Nynäs, Peter, Mika Lassander, and Terhi Utriainen. 2012. Post-Secular Society. New Brunswick: Transaction Publishers, ISBN 978-1-4128-4610-3.

Pajevic, Izet. 2012. Secular and postsecular psychiatry. Psychiatria Danubina 24: 262-66.

Pattison, Mansell E. 1978a. Psychiatry and Religion Circa 1978: Analysis of a decade, Part 1. In Pastoral Psychology. Orange: University of California Irvine Medical Center, Human Sciences Press, vol. 27, pp. 8-25.

Pattison, Mansell E. 1978b. Psychiatry and Religion Circa 1978: Analysis of a decade, Part 2. In Pastoral Psychology. Orange: University of California Irvine Medical Center, Human Sciences Press, vol. 27, pp. 119-41.

Poole, Rob, and Robert Higgo. 2011. Spirituality and the threat to therapeutic boundaries in psychiatric practice. Mental Health, Religion \& Culture 14: 19-29. [CrossRef]

Ruyter, Knut W. 2014. Space for Religion in Public Hospitals: Constructive Coexistence Can Be Negotiated. Edited by Rosemarie van den Breemer, Jose Casanova and Trygve Wyller. Göttingen: Vandenhoeck \& Ruprecht.

Taylor, Charles. 2007. A Secular Age. Cambridge: Harvard University Press, ISBN 978-0-674-02676-6.

Thielman, Samuel B. 2007. Spirituality and the Care of Madness: Historical Considerations. In Religion and Spirituality in Psychiatry. Edited by Huguelet, Philippe and Harold G. Koenig. Cambridge: Cambridge University Press, ISBN 978-0-521-88952-0.

Ulland, Dagfinn, and Valerie DeMarinis. 2014. Understanding and working with existential information in a Norwegian adolescent psychiatry context: A need and a challenge. Mental Health, Religion $\mathcal{E}$ Culture 17: 582-93. [CrossRef]

Zoglowek, Herbert. 1999. Tematisk analyse. En framgangsmåte for å analysere kvalitative intervju. Nordisk Pedagogik 19: 156-67.

(C) 2018 by the authors. Licensee MDPI, Basel, Switzerland. This article is an open access article distributed under the terms and conditions of the Creative Commons Attribution (CC BY) license (http://creativecommons.org/licenses/by/4.0/). 